FERMILAB-Conf-89/82

\title{
Longitudinal Damping in the TEVATRON Collider*
}

\author{
Q. A. Kerns, G. Jackson, C. R. Kerns, H. Miller, J. Reid, R. Siemann, and D. Wildman \\ Fermi National Accelerator Laboratory \\ P.O. Box 500, Batavia, Illinois 60510
}

March 1989

* Presented by Q. A. Kerns at the 1989 IEEE Particle Accelerator Conference, Chicago, Illinois, March 20-23, 1989.
Operated by Universities Research Association, Inc., under contract with the United States Department of Energy 
Ferni National Accelerator Laboratory* P.0. Box 500

Buteria, Ill. 80510

\section{Abstrect}

This paper describes the dauper design for 6 protion on 6 pbar bunches in the Teratron collider. 1 signal pichup, transient phase detection, derivative petwork, and phase correction vis the high-level if are covered. Bach if etution is controlled by a lon feedback loop. In addition, clobal feedback loops control each set of four cerities, one set for protons and one net for antiprotons. Operational experience vith these systens is discussed.

\section{Introduction}

lefer to Pigure 1. Note that only the pbar circuits are shom, but sotber complete set exists for protons.

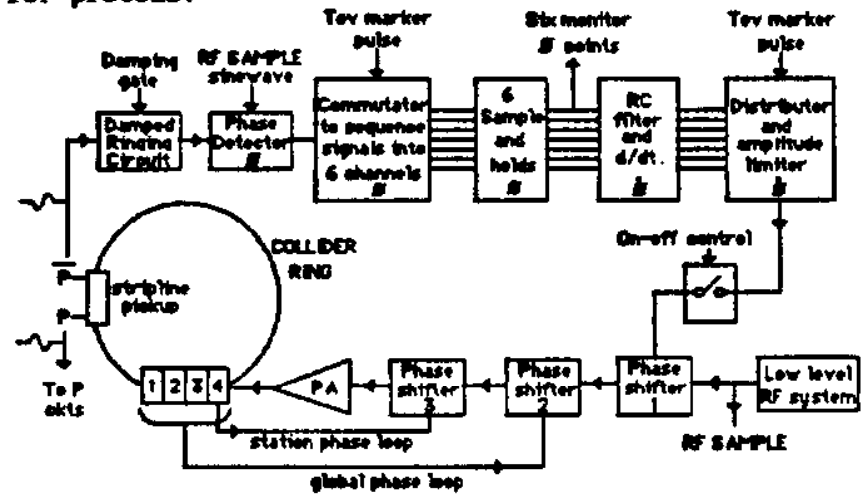

Pigure 1: Collider longitudinal damper for $6 \times 6$ bunches. (Diagran shows pbar cavity loops and damping channels only.)

The daper chain consists of a beam pjckup, a phase detector, a d/dt network to obtain \&, and a connection to phase ohifter $\| 1$ of the high-level if ursten.

The principle of the damer is described in Reference 2 . The phase of the entire 4-cavity bigh level accelerating oystem is ohifted rightly in response to a radiel position error $\Delta R$.

$$
\Delta R=-\frac{R}{F_{\pi f}} \times \frac{1}{2 \pi}
$$

where is is the rate-of-change of bunch phase relatire to low-level if phase.

Thether the danper circuitry is run open or closed-loop, using the witch show as On-Off Control" in Fig. 1, onitor vignals are available for -11 12 bunches in the machine throughout injection, acceleration and storage. At injection, these sicnals ellow one to readily mininise ny orstematic phose error between Mein Bing bunches and collider buckets.

\section{Pickup Locstion}

Individual $p$ and pbar bunches pass through the otripline directional pickup, which is 1 neter long and at roon tenperature but otherwise is like that described in leferences 3 and 4 . Directionslity of

- Operated by Universities Resenreb Association, Inc. under contract with the U.S. Department of Bnergy. the pickup is $-33 \mathrm{~dB}$ - insufficient to totslly diecrininate between $p$ and pbar bunches by directionality lone. We therefore placed the pickup at P17, dietant fron a collision point. The tine separation between $p$ and pbur busches at 817 is 1.75 nsec, adequate for conplete inolation by tine gating. There is, hoverer, one wort interval in wachine operation wen both $p$ 's and pbars pass through the pickup sinultaneously - that is during collision point cogging 5 . The danping loop thould be off during this cocging.

Ringing Circuit

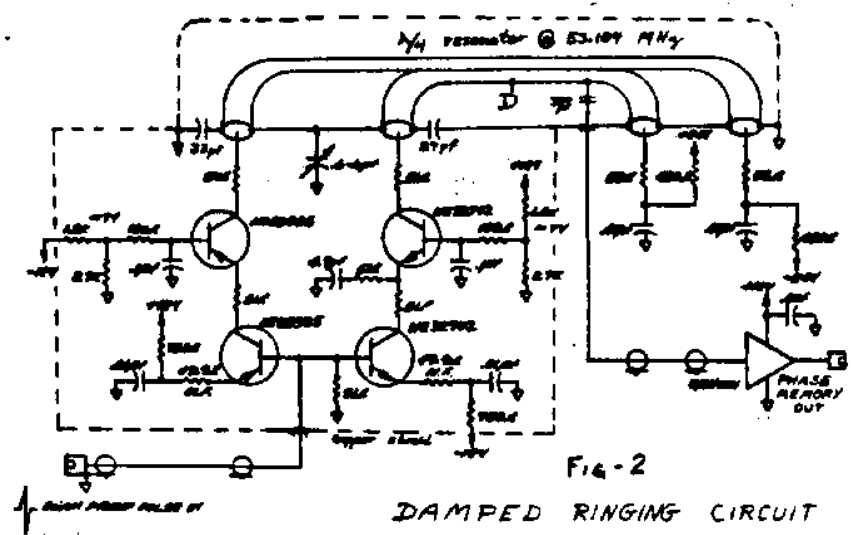

Figure 2 is the arrangenent to bellistically excite $a / 4$ resonator with the busch eignal. To elisinate anplitude-dependent phase changes related to excitation of the sinusoid, the bipolar pulse fron the pickup simultaneously feeds PNP and NPN transistors. At point $D$ in Figure 2 there is connected a dasping diode bridge to arrest the ringing before the next bunch arrives.

\section{Phase Detector, Cormutator and Sample-and-Bolds}

The phase detector, described in Reference 6, coupares the phase of the bunch-excited ringing with the lon-level if sinewave. Pbese detector output, an analogue signal of $1 \mathrm{rolt} / 0^{\circ}$, is gated into a sapleand-hold channel for 150 asec. Buch channel is individunlly updated turn by turn. The Tor arker pulse insures that the phase aignale are routed to the proper onple-and-hold chnnel.

\section{Sipal, Distributor and Liniter}

An active differentiator cenerates fros the cignal, os in Reference 2. The signals are -uccessively gated into phase ohifter \#1. Gating times are set to cause a new phase change to arrive at the high level cavities just as the previous bunch leaves. Doing this cires the naximun arailoble time for the carity phase to readjust to the nen ralue. The orailable tine between bunches of 1 epecies is onevixth of a turn or 3.5 nieroseconds.

Transiently, the phase abifter 1 an cover its full range, but a 375 nsec $R C$ netrork lisits the

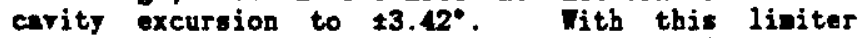
setting, there is no danger of tripping an rf tation. The $\$ 3.42^{\circ} \delta$ phase ahift corresponds to an individual bunch energy correction of $\mathrm{Vpk} s$ in $\delta \bullet \mathrm{V}$, or $172 \mathrm{KeV}$ 
per turn axinun, fires the typical ring roltage of 1.2 engrolts.

\section{AP Station and Global Phase Loops}

Bach if station has its ow slow phase feedback loop for phase trackins and poise reduction, providing -20 di improresent fros de to a fer hundred Berte. Carity gap roltage is conpared to the reference drive vis a phase detector. The error signal drives phase ahifter 3 to close the loop.

A fast clobal feedback loop controls each set of four carities; one set for protons and one net for antiprotons. Bach set of four carities is driven independantly. The two if sw aignals are conpared to their respective low lerel references by means of 150 nsec riwe tine phase detectors driving phase shifters 42. The proton and antiproton of sum signals take into account all eight carities in deriving proton and antiproton if roltage. These fast loops correct phise for tation trips and proride noise reduction in the operating grtex (mintsining collider luninosity). The loops hare $-20 \mathrm{~dB}$ gain with dc - $10 \mathrm{kBz}$ bandwidth.

\section{Operationsl Bxperience}

During the 1087 colliding beas run it ws observed that coherent synchrotron oscillations would develop orer a span of tens of ninutes. The present $6 \times 6$ phase foedbeck orstems was intended to rectify this.

At present the entiproton cysten is never turned on, and the proton oystem is active only during proton injection. The resson for this usage is explained.

\section{Injection}

One possible use of these phase feedback loops is to danp coherent oynchrotron oacillations induced by either a phase or energy error between the Main Ring and the Tevatron $f f$ systess at injection. Figure 3 contains a plot of the initial phese oscillation of a proton bunch. It turns out that the initial phase oscillation wefefore is virtually identical when the oxB phase feedback is turned on. Figure 4 contains the phase oscillation merefor of ainilur bunch as calculated by a computer sinulation. Note thet qualitatively the noevent betreen sinulation and the Teratron is rather reanarkble.

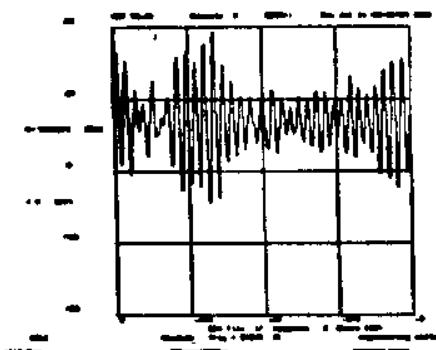

Pigure 3: 5yochrotron oecillation phase-proton bunch-Teratron injection.

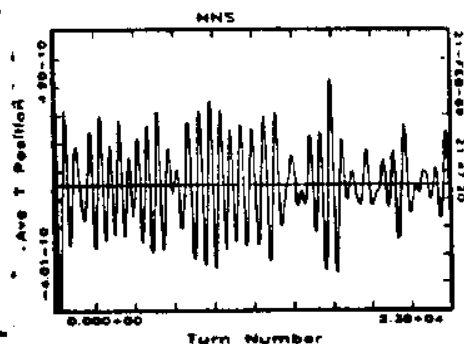

Figure 4: Bimulation of arnchrotron oreillation phase.
An will be whow later, the number of oscillations to dasp to $1 / \mathrm{e}$ of the original anplitude is 75 . Figure 5 ehows the phase upace distribution of the conputer sinulation test particles at 100 nsec. intervals, which turns out to be sbout 40 eynchrotron oscillations. Note that the large anplitude particles onear out into a unifors nisuthal density distribution far wore quickly than the core particlea, which even after 40 oscillations are luped closely together. As it turns out, it is observed that turning on the proton $6 \times 6$ greten at injection does not change the 95\% interval within wich the particles lie, but does alightly increase the core density of the bunch. Because of the very anall B* at BO, this helps increase the luninosity of the store.
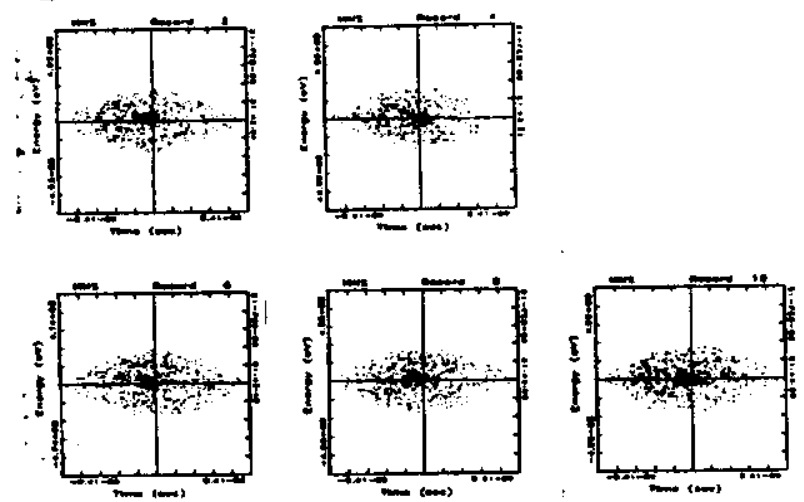

Pigure 5: Sinulation of longitudinal phase spece, showing that large aplitude particles sear into uniforn angular density distributions much faster than the core particles. Plots are apeced at 100 asec intervals.

\section{Colliding and Single Bear Storage}

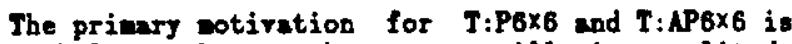
to stabilise the sychrotron oscillation applitude growth during long colliding beas stores. During the present collider run, this growth has only eppeared during proton-only wores, and with a growth rate ouch maller than that observed during the last collider run. During colliding bea stores, no spachrotron oscillation growth has been observed. A a result, these phase feedback loops are not used operationally during stores.

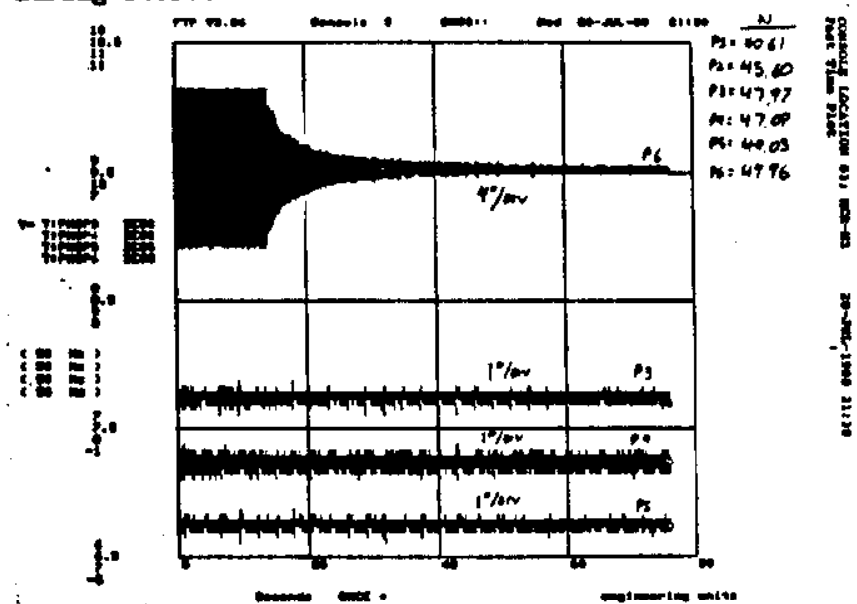

Pigure 6: Phase oscillation aplitude rs time in a proton only store.

During proton only stores, it has been repeatedly observed that individual bunches will begin to exbibit coherent eynchrotron oscillations with the loop off. This sotion is measured uring the $8 \times 6$ phase dectors. Pizure 6 shows the phase cotion of four bunches, labelled P3 through P6. Their intensities in units of $10^{9}$ particles per bunch are lieted on the left of the plot. Note that P6 has developed a very large teady tute phase oscillation. At 15 meconds into the plot, the I:P6x6 syaten was turned on. Note that the ation damped to $1 / \mathrm{e}$ of it original mplitude in bout 2 eeconds, which corresponds to the 75 wnchrotron oscilletions mentioned in the previous aection. It has been noted that it was the most intense bunch that experienced coherent oscillation growth, and sone effort has been ande to calculate a 
longitudinal inpedance from ubsequent neasurenents. The result is as jet inconclusive.

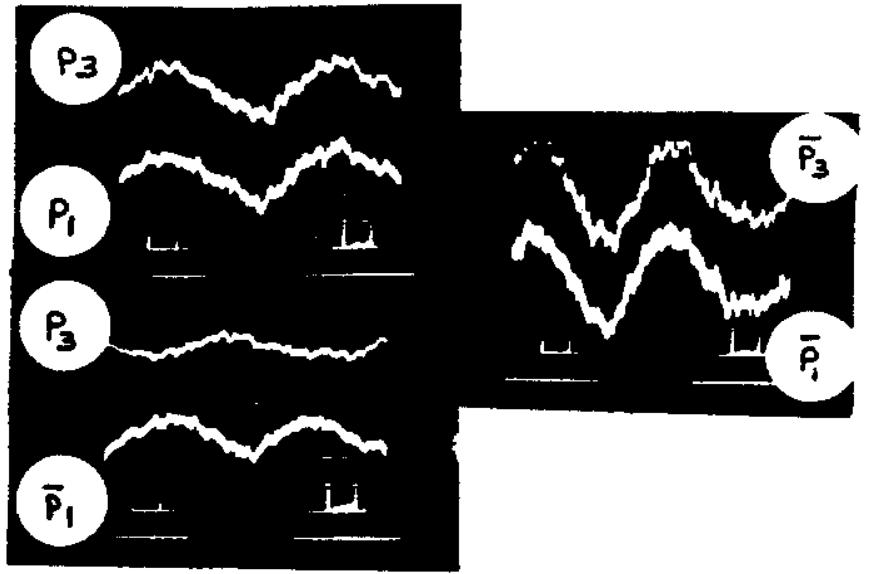

Pigure 7: Phare re tive for both $p$ and pbar.

Though growth in syachrotron oscillation aplitude bas not been observed during colliding bean running, there is : steady atste ras aplitude wich can be neasured. Pigure 7 contains three photographs of such oncillations. In the top photograph the top trace is $P 3$ and the botton trace is P1. Note that the oscillations have the sare inplitude and phase. In the right hand photograph, antiproton bunches $A 3$ and Al are sinilarly conpared, again exhibiting identical anplitude and phase. In the botton photograph, proton bunch P3 is compared to antiproton buncb A1. In contrast to the upper two photographs, these bunches are not oacillating together in phase. This conclusion has been rerified by looking at the cross coheerence of the two phase oscillations. Therefore, some slobal nechanies is affecting sll protons identically, all antiprotons identically, but affecting protons differently from entiprotons. An obrious candidate sechaniss is if phase noise, rince the proton and antiproton $r f$ cystens are independent. As yet no confiretion of this hypothesis has been forthconing.

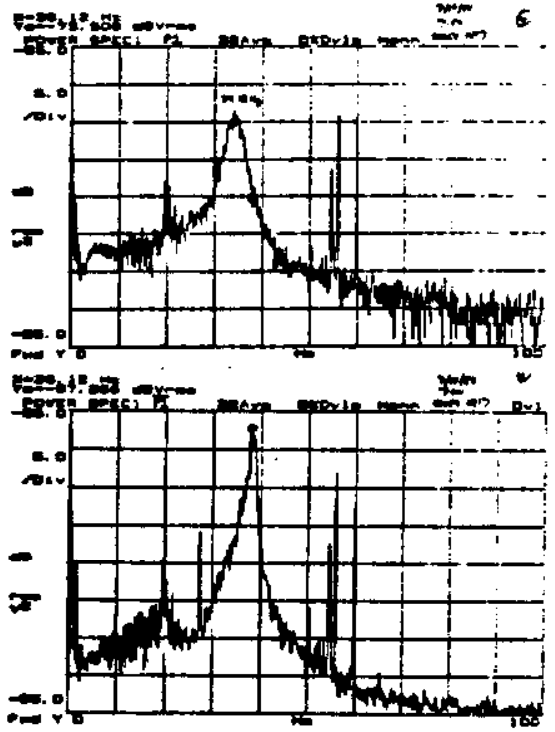

Pigure 8: Past Pourier transfora of phese ro tine date. Note that the proton and antiprotons have different oscillation frequencies and bandwidths.

Figure 8 conteins the Pourier transfore of the proton and antiproton motions. The bunch lengths of the proton bunches were longer than the antiproton bunches. Since the arochrotron frequency decresses quadratically with sjechrotron aplitude, one would expect the average arnchrotron frequency of the protons to be slightly lower and broader than the antiprotons, jutt os observed.

Since there exist coherent mpchrotron otion, one rould expect longitudinal enittance crowtb during a store. This is indeed the case, as denonstrated by the plot in Figure 0 . The crowth of these longitudinal enittances is not affected by $T: P 6 \times 6$.

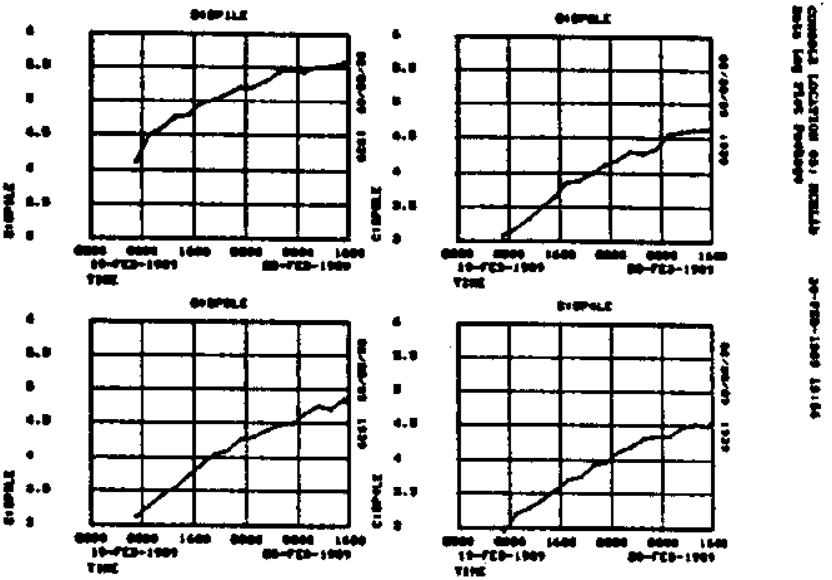

Figure 9: Longitudinal enittance ve tine for proton bunches one through four.

\section{Conclusions}

Prelininary masuremedts of the effect of the $8 \times 6$ phase feedback cystess in an operational netting have been ade. Due to the disappearance of the notivating sychrotron oscillation growth meacured in the last collider run, only the proton sjotes is useful, and only at injection.

Purther work is required to understand why coherent oscillation. develop in proton only stores, but not when proton-antiproton collisions take place. In addition, the wechanies of the proton only oscillation rowtb should be identified and fixed.

Figure 1 hows that the next candidate for inprovenent is the low-level if eysten, because at beat the danpins can only force the bunches to track the reference. Prelininary mesurenents indicate a potential inprovenent of 20 to $30 \mathrm{~dB}$ in lowering oscillator sideband noice in the 10 to 100 Eerte range which enconpasses the synchroton frequency.

\section{Peforences}

1. 1. Jolnson, "Initial Operation of the Collider", Proc. of 1087 IMEB Particles Ace. Conf., Washinton, D.C., Yureh 16-10, p. 8.

2. 8. Briftol ot il., The Tovatron Globsl Redius and os Systen", IFAB Trans. on Nuc. Sci. NS-3211 No. 5, p. 214, (1085)

3. R. B. Shafer et al., Pernilab Bnerc Doubler Beam Position Detector", N-28, No.3, p-2290 (1081).

4. B. E. 8hafer, Characteristics of Diractional Coupler Bana Position Nonitor:", IRER Trang. on Nuc. Bci., $\mathrm{FS}-32$, No.5, p-1933, (1985).

5. P. Martin t il. Antiproton Accoleration in the Pernilab Main Bing ad Terutron", in Proc. of 1087 IFET Part. Accel. Conf. Washincton, D.C., Yarch 10-10, p-47.

6 C. Kerns et al., Measuring the Orbit Lenght of the Teratron", IXIBE Trans. on Nucl. Sci., NS32. No. 5, p-1030, (1085).

7. q. Keras ot al., 'Fernilab Toratron Eigh Level rf Accelerating Systex", I IRE Trans. on Nuc. Sci., NS-32, No. 5, p-2800, (1985). 